\title{
Association of Various Systemic Factors with Intraocular Pressure
}

\author{
Pragati Garg*, Mohit Gupta, Swati Yadav, Luxmi Singh and Bharti Nigam
}

Department of Ophthalmology, Era's Lucknow Medical College, Lucknow, India

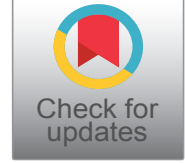

*Corresponding author: Pragati Garg, Department of Ophthalmology, Era's Lucknow Medical College, Lucknow, India

\begin{abstract}
Introduction: Raised intraocular pressure (IOP) is the principal modifiable risk factor for the development and progression of glaucoma. Glaucoma is defined as progressive optic neuropathy, based on visual field loss and/ or optic disc findings, is more likely to be associated with elevated intraocular pressure (IOP), although IOP is not the only risk factor for glaucomatous optic nerve damage. The complex physiology involved in aqueous humor formation and its maintenance indicates its dependence on other systemic, physical, physiological and environmental factors, thus effects IOP. The factors studied were age, gender, systemic blood pressure (BP) and body mass index (BMI).

Material and method: A cross sectional hospitalbased study was conducted where 800 adults of varying demographic profiles were included with their written and informed consent taken. A detailed history from all the patients including signs and symptoms of glaucoma was taken, demographic and anthropometric details noted. Ocular examination included visual acuity by Snellen's drum, refraction, intraocular pressure (IOP) by Goldman's applanation tonometer, gonioscopy using Zeiss fourmirror lens, visual field changes seen by Humphrey field analyzer (HFA) using 30-2 program (version 40), slit-lamp examination, fundus evaluation by both direct and indirect ophthalmoscopy, and 90D lens. The statistical analysis was done using SPSS (Statistical Package for Social Sciences) Version 15.0 statistical Analysis Software. The values were represented in Number (\%) and Mean \pm SD.
\end{abstract}

Results: Mean age of patients was $57.21 \pm 9.81$ years. With increasing age proportion of those with IOP up to $20 \mathrm{mmHg}$ showed a significant incremental trend. It was observed that mean age of subjects having $20-24 \mathrm{mmHg}$ IOP was minimum $(54.17 \pm 9.26$ years $)$ followed by $16-20 \mathrm{mmHg}$ (56.77 \pm 9.61 years), $12-16 \mathrm{mmHg}(58.50 \pm 9.73$ years), > $24 \mathrm{mmHg}(60.20 \pm 10.92$ years $)$ and $<12 \mathrm{mmHg}(61.56 \pm$ 7.54 years). Statistically, this difference was significant $(p<$ $0.001)$. There was a weak and inverse significant correlation between age and IOP $(r=-0.075 ; p=0.003)$. Majority of subjects were females (50.5\%). Proportion of those having IOP in $\leq 16 \mathrm{~mm}$ range was higher among males $(45.7 \%)$ as compared to that in females $(35.7 \%)$. Statistically, this difference was significant $(p<0.001)$. A weak positive and significant correlation was observed between IOP and BMI. Statistically, the difference in BMI of subjects in different IOP categories was significant $(p<0.001)$. Difference in mean IOP of normotensive $(16.95 \pm 3.35 \mathrm{mmHg})$ and hypertensives $(17.11 \pm 3.53 \mathrm{mmHg})$ was not found to be statistically significant. Mean SBP and DBP of subjects with IOP $<12 \mathrm{mmHg}, 20-24 \mathrm{mmHg}$ and $>24 \mathrm{mmHg}$ were found to be significantly higher as compared to those with IOP 16 - $20 \mathrm{mmHg}$ and $20-24 \mathrm{mmHg}$.

Conclusion: The present study shows the association between age, gender, BMI and blood pressure, depicting the multivariable of IOP. Thus, the measurement of IOP is essential in all the patients with variable demographic, anthropometric, or systemic profile, thereby aiding in evaluation and diagnosis of various forms of glaucoma.

\section{Keywords}

IOP, Age, Gender, Systemic blood pressure, BMI

\section{Introduction}

Raised intraocular pressure (IOP) is the principal modifiable risk factor for the development and progression of glaucoma [1,2]. Glaucoma is defined as progressive optic neuropathy, based on visual field loss and/or optic disc findings. It is more likely to be associated with elevated intraocular pressure (IOP), although IOP is not the only risk factor for glaucomatous optic nerve damage [3], for it definitely is the principle modifiable risk factor for the development and progression of glaucoma.

IOP is generated by the flow of aqueous humor against resistance and is necessary for the proper shape and optical properties of the globe [4]. Regulation of IOP is a complex physiologic trait that depends on the production of aqueous humor $(\mathrm{AH})$, resistance to 
aqueous humor outflow, and episcleral venous pressure [5]. The intraocular pressure (IOP) is the hydrostatic pressure exerted by the $\mathrm{AH}$.

The complex physiology involved in aqueous humor formation and its maintenance indicates its dependence on various systemic, physical, physiological and environmental factors. IOP is the outcome of a multivariate relationship of different systemic, biometric, biological and environmental factors, in which these factors might have varying role with variable weight, moreover, some of these factors are mutually interrelated and as such their relationship with IOP is confounded by interplay of these factors.

\section{Material and Method}

A cross sectional hospital-based study was conducted, where 800 healthy adults of varying demographic profiles were included with their written and informed consent taken.

Patients excluded from the study were those having phthisis bulbi, uveitis, pterygium involving cornea, corneal opacity, previously diagnosed glaucoma, history of any medications effecting IOP, moderate to severe strabismus, difficulties in measuring IOP, history of intraocular surgeries including laser iridotomy, history of ocular trauma.

A detailed ocular and systemic history from all the patients including signs and symptoms of glaucoma was taken. The demographic and anthropometric details were also noted. BMI was calculated using the formula weight in kilograms divided by the square of the height in metres $\left(\mathrm{kg} / \mathrm{m}^{2}\right)$ and categories as Underweight (< 18.5) Normal (18.5 - 24.9) Overweight (25.0 - 29.9) Obese $(\geq 30)[6]$.

Ocular examination included visual acuity by Snellen's drum, refraction, intraocular pressure (IOP) by Goldman's applanation tonometer, gonioscopy using Zeiss four-mirror lens, visual field changes seen by Humphrey field analyzer (HFA) using 30 - 32 program (version 40), slit-lamp examination, fundus evaluation by both direct and indirect ophthalmoscopy, and 90D lens. Systemic blood pressure was recorded by sphygmomanometer and hypertensives identified by criteria of JMC-7 (2003), as a persistent elevation of blood pressure $>140 / 90 \mathrm{mmHg}$.

The statistical analysis was done using SPSS (Statistical Package for Social Sciences) Version 15.0 statistical Analysis Software. The values were represented in Number (\%) and Mean \pm SD. To test the significance of the means the student ' $\mathrm{t}$ ' test was used. The ANOVA test was used to compare the within group and between group variability amongst the study groups. ANOVA provided " $F$ " ratio, where a higher " $F$ " value depicted a higher inter-group difference. The Pearson coefficient was found to denote the level of correlation
Table 1: Age and Gender profile of study population $(n=800)$.

\begin{tabular}{|c|c|c|c|}
\hline SN & Characteristic & Stat & \\
\hline 1. & Mean Age \pm SD (Range) in years & 57.2 & $1(26-85)$ \\
\hline 2. & Gender & No. & $\%$ \\
\hline & Male & 396 & 49.5 \\
\hline & Female & 404 & 50.5 \\
\hline 3. & $\mathrm{BMI}\left(\mathrm{kg} / \mathrm{m}^{2}\right)$ & & \\
\hline & Underweight $(<18.5)$ & 15 & 1.9 \\
\hline & Normal (18.5 - 24.9) & 472 & 59.0 \\
\hline & Overweight (25.0 - 29.9) & 248 & 31.0 \\
\hline & Obese $(\geq 30)$ & 65 & 8.1 \\
\hline 4. & Blood pressure & & \\
\hline & Normotensive $(<90 / 140)$ & 665 & 83.1 \\
\hline & Hypertensive (> 90/140) & 135 & 16.9 \\
\hline 5. & IOP $(\mathrm{mmHg})$ & $(n=$ & \\
\hline & $<12$ & 9 & 0.6 \\
\hline & $12-16$ & 642 & 40.1 \\
\hline & $16-20$ & 706 & 44.1 \\
\hline & $20-24$ & 183 & 11.4 \\
\hline & $>24$ & 60 & 3.8 \\
\hline
\end{tabular}

between two variables with $r<0.3$ showing weak or no correlation, $r=0.3$ to 0.5 mild correlation, $r=0.5$ to 0.7 moderate correlation, $r=0.7$ to 0.9 Strong correlation and $r>0.9$ very strong to perfect correlation.

\section{Results}

A total of 800 patients falling into the sampling frame were studied. The age of patients ranged from 26 to 85 years with a mean age of $57.21 \pm 9.81$ years. The male female ratio was 0.98 . Majority of patients were in normal BMI category (59\%) followed by overweight $(31 \%)$, obese $(8.1 \%)$ and underweight (1.9\%) category. $16.9 \%$ patients were hypertensive, and rest were normotensive (83.1) (Table 1).

With increasing age, the proportion of those with IOP up to $20 \mathrm{mmHg}$ showed a significant increasing trend. The mean IOP of those aged 41 - 60 years was minimum $(16.92 \pm 3.22 \mathrm{mmHg})$ followed by those aged $>60$ years $(16.98 \pm 3.65 \mathrm{mmHg})$ and $<40$ years $(17.68 \pm 3.30 \mathrm{mmHg})$ respectively. Statistically, difference in mean IOP among different age groups was not significant $(p=0.141)$. The mean age of subjects in different IOP categories showed an inverted hyperbolic trend. It was observed that mean age of subjects having $20-24 \mathrm{mmHg}$ IOP was minimum ( $54.17 \pm 9.26$ years) followed by $16-20 \mathrm{mmHg}(56.77$ \pm 9.61 years), $12-16 \mathrm{mmHg}(58.50 \pm 9.73$ years $),>24$ $\mathrm{mmHg}(60.20 \pm 10.92$ years $)$ and $<12 \mathrm{mmHg}(61.56 \pm$ 7.54 years). Statistically, this difference was significant $(p<0.001)$. Pearson correlation showed a weak and inverse significant correlation between age and IOP $(r=$ -0.075; $p=0.003$ ) (Table 2).

The association between gender and IOP was studied and we found that proportion of those having IOP in $\leq 16 \mathrm{~mm}$ range was higher among males (45.7\%) as compared to females (35.7\%). Statistically, this difference was significant $(p<0.001)$. Although mean IOP of males was lower $(16.91 \pm 3.55 \mathrm{mmHg})$ as compared 
A) Age Category and IOP Category.

Table 2: Association between Age and IOP.

\begin{tabular}{|c|c|c|c|c|c|c|c|c|c|c|c|c|}
\hline \multirow[t]{2}{*}{ SN } & \multirow[t]{2}{*}{ Age Category } & \multirow[t]{2}{*}{ No. } & \multicolumn{2}{|c|}{$<12 \mathrm{mmHg}(\mathrm{n}=9)$} & \multicolumn{2}{|c|}{$\begin{array}{l}12-16 \mathrm{mmHg} \\
(642)\end{array}$} & \multicolumn{2}{|c|}{$\begin{array}{l}16-20 \mathrm{mmHg} \\
(\mathrm{n}=706)\end{array}$} & \multicolumn{2}{|c|}{$20-24 \mathrm{mmHg}(\mathrm{n}=183)$} & \multicolumn{2}{|c|}{$>24 \mathrm{mmHg}(n=60)$} \\
\hline & & & No. & $\%$ & No. & $\%$ & No. & $\%$ & No. & $\%$ & No. & $\%$ \\
\hline 1. & $<40$ years & 84 & 0 & 0.0 & 29 & 34.5 & 33 & 39.3 & 20 & 23.8 & 2 & 2.4 \\
\hline 2. & $41-60$ years & 968 & 4 & 0.4 & 384 & 39.7 & 422 & 43.6 & 133 & 13.7 & 25 & 2.6 \\
\hline 3. & $>60$ years & 548 & 5 & 0.9 & 229 & 41.8 & 251 & 45.8 & 30 & 5.5 & 33 & 6.0 \\
\hline
\end{tabular}
$X^{2}=48.235 ; p<0.001$.

B) Age Category and Mean IOP.

\begin{tabular}{|l|l|l|l|l|}
\hline SN & Age Category & No. of cases & IOP & SD \\
\hline 1. & $<40$ years & & Mean & 17.68 \\
\hline 2. & $41-60$ years & 84 & 16.92 & 3.30 \\
\hline 3. & $>60$ years & 968 & 16.98 & 3.22 \\
\hline
\end{tabular}

$F=1.959 ; p=0.141$ (ANOVA).

C) IOP Category and Mean Age.

\begin{tabular}{|l|l|l|l|l|}
\hline SN & IOP Category & No. of cases & Age & Mean \\
\hline 1. & $<12 \mathrm{mmHg}$ & 9 & 61.56 & 7.54 \\
\hline 2. & $12-16 \mathrm{mmHg}$ & 642 & 58.50 & 9.73 \\
\hline 3. & $16-20 \mathrm{mmHg}$ & 706 & 56.77 & 9.61 \\
\hline 4. & $20-24 \mathrm{mmHg}$ & 183 & 53.17 & 9.26 \\
\hline 5. & $>24 \mathrm{mmHg}$ & 60 & 60.20 & 10.92 \\
\hline
\end{tabular}

$F=13.125 ; p<0.001$.

D) Correlation (Pearson correlation).

\begin{tabular}{|l|l|l|}
\hline Variable & 'r' & 'p' \\
\hline Age vs IOP & -0.075 & 0.003 \\
\hline
\end{tabular}

There was a weak and inverse significant correlation between age and IOP $(r=-0.075 ; p=0.003)$.

(a) Gender and IOP Category.

Table 3: Association between Gender and IOP.

\begin{tabular}{|c|c|c|c|c|c|c|c|c|c|c|c|c|}
\hline \multirow[t]{2}{*}{ SN } & \multirow[t]{2}{*}{ Gender } & \multirow[t]{2}{*}{ No. } & \multicolumn{2}{|c|}{$<12 \mathrm{mmHg}(\mathrm{n}=9)$} & \multicolumn{2}{|c|}{12 - $16 \mathrm{mmHg}(642)$} & \multicolumn{2}{|c|}{$16-20 \mathrm{mmHg}(\mathrm{n}=706)$} & \multicolumn{2}{|c|}{$\begin{array}{l}20-24 \mathrm{mmHg} \\
(\mathrm{n}=183)\end{array}$} & \multicolumn{2}{|c|}{$>24 \mathrm{mmHg}(\mathrm{n}=60)$} \\
\hline & & & No. & $\%$ & No. & $\%$ & No. & $\%$ & No. & $\%$ & No. & $\%$ \\
\hline 1. & Male & 792 & 4 & 0.5 & 358 & 45.2 & 289 & 36.5 & 112 & 14.1 & 29 & 3.7 \\
\hline 2. & Female & 808 & 5 & 0.6 & 284 & 35.1 & 417 & 51.6 & 71 & 8.8 & 31 & 3.8 \\
\hline
\end{tabular}

$X^{2}=40.944 ; p<0.001$ (Chi-square test).

(b) Gender and Mean IOP.

\begin{tabular}{|c|c|c|c|c|}
\hline \multirow[t]{2}{*}{ SN } & \multirow[t]{2}{*}{ Gender } & \multirow[t]{2}{*}{ No. of cases } & \multicolumn{2}{|l|}{ IOP } \\
\hline & & & Mean & SD \\
\hline 1. & Male & 792 & 16.91 & 3.55 \\
\hline 2. & Female & 808 & 17.05 & 3.21 \\
\hline
\end{tabular}

$T=-0.835 ; p=0.404$ (Independent samples 't'-test).

to females $(17.05 \pm 3.21 \mathrm{mmHg}$ ) yet this difference was not significant statistically $(p=0.404)$ (Table 3$)$.

When association between BMI and IOP was evaluated, we found that among underweight patients IOP ranged between $12-16 \mathrm{mmHg}$ in most of them $(66.7 \%)$ and 16 - $20 \mathrm{mmHg}$ among normal weight (46.7\%), overweight (40.9\%) and obese (47.7\%) patients. Statistically, these proportional differences were significant $(p<0.001)$. Mean IOP values of underweight, normal weight, overweight and obese subjects were
$16.60 \pm 2.88 \mathrm{mmHg}, 16.61 \pm 2.89 \mathrm{mmHg}, 17.29 \pm 3.67$ $\mathrm{mmHg}$ and $18.53 \pm 4.82 \mathrm{mmHg}$ respectively, thus showing an increasing IOP trend with increasing $\mathrm{BMI}$ of patients ( $p<0.001)$. Mean BMI of subjects having IOP $<12 \mathrm{mmHg}$ to $20-24 \mathrm{mmHg}$ ranged from $23.89 \pm 2.10$ $\mathrm{kg} / \mathrm{m}^{2}$ to $24.74 \pm 3.30 \mathrm{~kg} / \mathrm{m}^{2}$, however, mean BMl of those having IOP > $24 \mathrm{mmHg}$ was $27.90 \pm 4.02 \mathrm{~kg} / \mathrm{m}^{2}$. Statistically, the difference in BMI of subjects in different IOP categories was significant $(p<0.001)$ (Table 4). A weak and significant correlation was observed between IOP and BMI ( $r=0.173, p<0.001)$. 
(a) BMI and IOP Category.

Table 4: Association between BMI and IOP.

\begin{tabular}{|c|c|c|c|c|c|c|c|c|c|c|c|c|}
\hline \multirow[t]{2}{*}{ SN } & \multirow[t]{2}{*}{ BMI $\left(\mathbf{k g} / \mathbf{m}^{2}\right)$} & \multirow[t]{2}{*}{ No. } & \multicolumn{2}{|c|}{$\begin{array}{l}<12 \mathrm{mmHg} \\
(\mathrm{n}=9)\end{array}$} & \multicolumn{2}{|c|}{$\begin{array}{l}12-16 \mathrm{mmHg} \\
(642)\end{array}$} & \multicolumn{2}{|c|}{$\begin{array}{l}16-20 \mathrm{mmHg} \\
(\mathrm{n}=706)\end{array}$} & \multicolumn{2}{|c|}{$\begin{array}{l}20-24 \mathrm{mmHg} \\
(\mathrm{n}=183)\end{array}$} & \multicolumn{2}{|c|}{$>24 \mathrm{mmHg}(\mathrm{n}=60)$} \\
\hline & & & No. & $\%$ & No. & $\%$ & No. & $\%$ & No. & $\%$ & No. & $\%$ \\
\hline 1. & Underweight $(<18.5)$ & 30 & 0 & 0.0 & 20 & 66.7 & 0 & 0.0 & 10 & 33.3 & 0 & 0.0 \\
\hline 2. & $\begin{array}{l}\text { Normal } \\
(18.5-24.9)\end{array}$ & 944 & 6 & 0.6 & 386 & 40.9 & 441 & 46.7 & 99 & 10.5 & 12 & 1.3 \\
\hline 3. & $\begin{array}{l}\text { Overweight (25.0 - } \\
29.9)\end{array}$ & 496 & 3 & 0.6 & 198 & 39.9 & 203 & 40.9 & 62 & 12.5 & 30 & 6.0 \\
\hline 4. & Obese $(\geq 30)$ & 130 & 0 & 0.0 & 38 & 29.2 & 62 & 47.7 & 12 & 9.2 & 18 & 13.8 \\
\hline
\end{tabular}

$X^{2}=99.74 ; p<0.001$ (Chi-square test).

(b) BMI and Mean IOP.

\begin{tabular}{|l|l|l|l|l|}
\hline $\mathbf{S N}$ & $\mathbf{B M I}\left(\mathbf{k g} / \mathbf{m}^{\mathbf{2}}\right)$ & No. of cases & IOP & Mean \\
\hline 1. & Underweight $(<18.5)$ & & 16.60 & 2.88 \\
\hline 2. & Normal $(18.5-24.9)$ & 30 & 16.61 & 2.89 \\
\hline 3. & Overweight $(25.0-29.9)$ & 944 & 17.29 & 3.67 \\
\hline 4. & Obese $(\geq 30)$ & 496 & 18.53 & 4.82 \\
\hline
\end{tabular}

$F=14.75 ; p<0.001$ (ANOVA).

(c) C) IOP and Mean BMI.

\begin{tabular}{|l|l|l|l|l|}
\hline SN & IOP Category & No. of cases & BMI & Mean \\
\hline 1. & $<12 \mathrm{mmHg}$ & 9 & 23.89 & SD \\
\hline 2. & $12-16 \mathrm{mmHg}$ & 642 & 24.12 & 2.10 \\
\hline 3. & $16-20 \mathrm{mmHg}$ & 706 & 24.74 & 3.30 \\
\hline 4. & $20-24 \mathrm{mmHg}$ & 183 & 24.33 & 3.51 \\
\hline 5. & $>24 \mathrm{mmHg}$ & 60 & 27.90 & 3.89 \\
\hline
\end{tabular}

$F=33.86 ; p<0.001$ (ANOVA).

(d) Correlation (Pearson correlation).

\begin{tabular}{|l|l|l|}
\hline Variable & $R$ & 'p' \\
\hline BMI vs. IOP & 0.173 & $<0.001$ \\
\hline
\end{tabular}

In this study majority of the patients were normotensive (83.1\%). In both the blood pressure categories, maximum had IOP in $16-20 \mathrm{mmHg}$ range with no significant association between IOP and blood pressure status. The mean IOP of normotensive subjects was lower $(16.95 \pm 3.95 \mathrm{mmHg})$ as compared to that of hypertensive subjects $(17.11 \pm 3.53 \mathrm{mmHg}$ ), however, this difference also was not found to be significant statistically ( $p=0.469$ ). Mean systolic blood pressure was minimum among those having IOP 12 - 16 $\mathrm{mm}(127.74 \pm 14.00 \mathrm{mmHg})$ followed by $16-20 \mathrm{mmHg}$ (128.03 \pm 4.08$), 20-24 \mathrm{mmHg}(131.45 \pm 11.77 \mathrm{mmHg})$, $>24 \mathrm{mmHg}(132.43 \pm 12.75 \mathrm{mmHg})$ and $<12 \mathrm{mmHg}$ $(134.22 \pm 15.92 \mathrm{mmHg})$ respectively. Statistically, difference in systolic blood pressure among different IOP categories was significant $(p=0.001)$.

In both the blood pressure categories, maximum had IOP in $16-20 \mathrm{mmHg}$ range followed by $12-16 \mathrm{mmHg}, 20$ - $24 \mathrm{mmHg}$, > $24 \mathrm{mmHg}$ and $<12 \mathrm{mmHg}$ category. Statistically, there was no significant association between IOP category and blood pressure status ( $p=0.089)$.

Mean diastolic blood pressure was minimum among those having IOP $16-20 \mathrm{~mm}(80.61 \pm 8.78 \mathrm{mmHg})$ followed by $20-24 \mathrm{mmHg}(81.20 \pm 8.96 \mathrm{mmHg}), 12-$ $16 \mathrm{mmHg}(81.63 \pm 7.70 \mathrm{mmHg}),<12 \mathrm{mmHg}(82.67 \pm$ $6.56 \mathrm{mmHg})$ and $>24 \mathrm{mmHg}(85.13 \pm 10.44 \mathrm{mmHg})$ respectively. Statistically, difference in diastolic blood pressure among different IOP categories was significant $(p=0.001)$. There was a weak positive and significant correlation between SBP and IOP ( $r=0.057 ; p=0.022)$. The correlation between DBP and IOP was weak positive and statistically non-significant $(r=0.027 ; p=0.327)$ (Table 5).

In a multivariate model where IOP (> $16 \mathrm{mmHg}$ ) was projected as a dependent variable with age, gender, systolic blood pressure, diastolic blood pressure as independent variables, gender, systolic blood pressure and BMI showed a significant association with the outcome IOP (Table 6).

\section{Discussion}

Despite a definitive role in causation of ocular ailments, the exact pathophysiology and factors affecting the intraocular pressure is not clearly understood. 
(a) BP and IOP Category.

Table 5: Association between Blood Pressure and IOP.

\begin{tabular}{|c|c|c|c|c|c|c|c|c|c|c|c|c|}
\hline \multirow[t]{2}{*}{ SN } & \multirow[t]{2}{*}{$\begin{array}{l}\text { Blood Pressure } \\
\text { Status }\end{array}$} & \multirow[t]{2}{*}{ No. } & \multicolumn{2}{|c|}{$<12 \mathrm{mmHg}(\mathrm{n}=9)$} & \multicolumn{2}{|c|}{$\begin{array}{l}12-16 \mathrm{mmHg} \\
(642)\end{array}$} & \multicolumn{2}{|c|}{$\begin{array}{l}16-20 \mathrm{mmHg} \\
(\mathrm{n}=706)\end{array}$} & \multicolumn{2}{|c|}{$\begin{array}{l}20-24 \mathrm{mmHg} \\
(\mathrm{n}=183)\end{array}$} & \multicolumn{2}{|c|}{$>24 \mathrm{mmHg}(\mathrm{n}=60$} \\
\hline & & & No. & $\%$ & No. & $\%$ & No. & $\%$ & No. & $\%$ & No. & $\%$ \\
\hline 1. & Normotensive & 1330 & 6 & 0.5 & 545 & 41.0 & 580 & 43.6 & 155 & 11.7 & 44 & 3.3 \\
\hline 2. & Hypertensive & 270 & 3 & 1.1 & 97 & 35.9 & 126 & 46.7 & 28 & 10.4 & 16 & 5.9 \\
\hline
\end{tabular}

$X^{2}=8.065 ; p=0.089$ (Chi-square test).

(b) BP and Mean IOP.

\begin{tabular}{|l|l|l|l|l|}
\hline SN & Blood Pressure & No. of cases & IOP & Mean \\
\hline 1. & Normotensive & 1330 & 16.95 & 3.35 \\
\hline 2. & Hypertensive & 270 & 17.11 & 3.53 \\
\hline
\end{tabular}

$T=-0.725 ; p=0.469$ (Independent samples't'-test).

(c) IOP and Mean Blood pressure.

\begin{tabular}{|l|l|l|l|l|l|l|}
\hline SN & IOP Category & No. of cases & SBP & \multicolumn{3}{l|}{ DBP } \\
\cline { 5 - 7 } & & & Mean & SD & Mean & SD \\
\hline 1. & $<12 \mathrm{mmHg}$ & 9 & 134.22 & 15.92 & 82.67 & 6.56 \\
\hline 2. & $12-16 \mathrm{mmHg}$ & 642 & 127.74 & 14.00 & 81.63 & 7.70 \\
\hline 3. & $16-20 \mathrm{mmHg}$ & 706 & 128.03 & 14.08 & 80.61 & 8.78 \\
\hline 4. & $20-24 \mathrm{mmHg}$ & 183 & 131.45 & 11.77 & 81.20 & 8.96 \\
\hline 5. & 60 & 132.43 & 12.75 & 85.13 & 10.44 \\
\hline F (ANOVA) & & & 4.419 & & 4.582 & \\
\hline 'p' & & & 0.001 & & 0.001 \\
\hline
\end{tabular}

(d) Correlation (Pearson correlation).

\begin{tabular}{|l|l|l|}
\hline Variable & $\mathbf{R}$ & 'p' \\
\hline SBP vs. IOP & 0.057 & 0.022 \\
\hline DBP vs. IOP & 0.027 & 0.327 \\
\hline
\end{tabular}

Table 6: Multivariate Regression.

\begin{tabular}{|l|l|l|l|l|l|l|}
\hline & B & S.E. & Wald & Df & Sig. & Exp (B) \\
\hline Age & -0.027 & 0.006 & 22.817 & 1 & 0.000 & 0.974 \\
\hline Gender & 0.354 & 0.107 & 10.993 & 1 & 0.001 & 1.425 \\
\hline SBP & 0.018 & 0.005 & 14.023 & 1 & 0.000 & 1.018 \\
\hline DBP & -0.020 & 0.008 & 6.910 & 1 & 0.009 & 0.980 \\
\hline BMI & 0.063 & 0.016 & 15.982 & 1 & 0.000 & 1.065 \\
\hline Constant & -1.103 & 1.050 & 1.104 & 1 & 0.293 & 0.332 \\
\hline
\end{tabular}

In our study a total of 800 healthy individuals falling in sampling frame were included in the assessment. Age of patients in the study sample ranged from 26 to 85 years of age, with a mean age of 57.21 years. Male:female ratio was 0.98 and was predominantly having normal BMI (59\%), however, a large proportion (39.1\%) of our study population was overweight and obese. There were 135 (16.9\%) hypertensives and 665 $(83.1 \%)$ were normotensives.

In present study, although with increasing age proportion of those with IOP up to $20 \mathrm{mmHg}$ showed a significant increasing trend, on evaluating the mean IOP in different age groups, the difference was not found to be significant. However, on evaluating the mean age of patients a non-linear and yet statistically significant association with increasing IOP values was observed. Strangely, the mean age of those having IOP in $20-24$ $\mathrm{mmHg}$ range was minimum (53.17 years) as compared to other IOP categories for which the mean age varied from 56.77 to 61.56 years. On evaluating the linear correlation between age and IOP, it was found to be weak inverse but statistically significant. All these findings suggested a complex relationship between IOP an age. The existence of a significant association on evaluating categorically but lacking consistency when evaluated for linearity shows that the relationship between IOP and age is confounded and requires further exploration. The findings of present study are similar to the observations made by Wong, et al. (2009) [7] who observed that IOP increased with age to the sixth decade, after which a decrease in IOP is seen resulting in an inverted $U$ pattern. In present study, we also observed a similar non-linear relationship between IOP and age. However, Tomoyose, et al. [8] in their study showed that higher IOP was significantly correlated with younger age $(r=$ $-0.11 ; p<0.001)$. Although, in present study, we found a similar inverse correlation between age and IOP ( $r=$ 
$-0.071 ; p<0.001$ ) yet we considered it to have negligible impact.

In present study, we found a significant association between gender and IOP on categorical evaluation and found that proportion of those having IOP in $\leq 16 \mathrm{~mm}$ range was higher among males (45.7\%) as compared to that in females (35.7\%). However, on evaluating the mean IOP of males and females, this difference was not found to be significant. Similar to our study, a number of other workers have also found no significant difference in mean IOP of males and females [8]. In their study, Zainab, et al. [9] noted an interesting relationship between IOP, BMI and gender. They observed that a change of $1 \mathrm{~kg} / \mathrm{m}^{2}$ in BMl corresponded with a change in IOP by $0.23 \mathrm{mmHg}$ in males and $0.14 \mathrm{mmHg}$ in females, thus showing that the relationship between IOP and gender is affected by BMI.

In present study, we found that lower IOPs were associated with lower $\mathrm{BMI}$ and in underweight to obese $\mathrm{BMI}$ categories there was a significantly increasing trend of mean IOP of patients. The correlation was thus linear, positive and significant. The relationship between BMI and IOP has been extensively explored and most of the studies similar to our study confirm existence of a significant relationship between BMI and IOP [8-12].

The present study also enquired into the relationship between IOP and blood pressure. In present study, no significant impact of hypertension on IOP was observed. However, when evaluated independently both systolic blood pressure and diastolic blood pressure showed a significant association with IOP levels. IOP also had a weak positive but statistically significant correlation with systolic blood pressure. The relationship between blood pressure and intraocular pressure was analyzed in a prospective study by $\mathrm{Wu}$, et al. [13], who in population of 2298 individuals of African descent prospectively evaluated blood pressure changes and IOP changes over a period of 9 years and found hypertension, and higher systolic and diastolic blood pressure at baseline were associated with increase in IOP after 9 years. The present study varied from the cited study as it was only a cross-sectional study and made evaluation at one time only. As far as independent association of systolic and diastolic blood pressure is concerned, a number of previous studies have supported this relationship. Wong, et al. [7] in a cross-sectional study like ours, found SBP as a significant determinant of IOP. In younger persons 40 to 59 years of age, both CCT and SBP were significant determinants of IOP $(P<0.001$ for both), but in older persons (60 to 80 years), age and SBP, but not CCT, were significant determinants of IOP $(P=$ 0.001 for age, $P<0.001$ for SBP). Similarly, Tomosyose, et al. [8] also found that higher SBP was associated with higher IOP. In present study, a significant weak positive correlation between IOP and SBP levels was observed ( $r=0.057 ; p=0.022$ ), however, Ngo, et al.
[14] in their study reported it to be even stronger ( $r$ $=0.36 ; \mathrm{p}=0.043$ ). In present study, we also observed the association between mean IOP and diastolic blood pressure but did not find this relationship linear. On calculating the Pearson correlation coefficient, it was found to be weakly positive and statistically nonsignificant ( $r=0.027 ; p=0.327$ ). On evaluating the literature reviewed by us, we found only a single study that has shown the role of diastolic blood pressure in determination of IOP change [13]. In multivariate analyses, IOP changes were positively associated with male sex, hypertension, diabetes history, and higher systolic and diastolic blood pressure at baseline, as well as with increases in blood pressure throughout 9 years (P.05). The evidence for a positive relationship between DBP and IOP is contradictory. Higher DBP was associated with elevated IOP, however the association was not as strong as between SBP and elevated IOP [15]. On multivariate analysis the correlation between SBP and IOP continued to be strong, whereas the correlation between DBP and IOP weakened to $0.09 \%$. In contrast to this study, BLSA and the Japanese studies have demonstrated no apparent correlation between DBP and IOP [16-18]. Therefore, it can be stated that the association between DBP and IOP is not substantiated and needs further evaluation.

The present study had an extensive coverage of variables that might affect IOP. In order to elaborate the role of independent factors associated with IOP, we carried out a multivariate analysis. In a multivariate model where IOP (> $16 \mathrm{mmHg}$ ) was projected as a dependent variable with age, gender, systolic blood pressure, diastolic blood pressure, BMI as independent variables, gender, systolic blood pressure and BMI showed a significant association with the outcome IOP.

In different multivariate models projected in previous works different independent predictors have emerged as predictors of IOP. Tomoyose, et al. [8] projected a model that had younger age, higher SBP, higher BMI, history of diabetes mellitus, as the predictors of higher IOP. However, out of these, in present study, systolic blood pressure, BMI emerged as the significant predictors of IOP. Kim, et al. [19] in their multivariate assessment found higher IOP to be associated with male sex, higher myopic refractive error, higher body mass index, higher systolic blood pressure, higher fasting plasma glucose and higher total cholesterol. In present study we did not make an assessment of cholesterol levels, refractive error, blood sugar levels. Despite this dissimilarity, the two significant predictors in the present study, SBP and BMI, were found to be predictors of higher IOP in their study. Hashemi, et al. [11] in their multivariate model had sex, diabetes, SBP, BMI, education, CCT and myopic shift to be significant independent predictors of IOP. Of all these significant predictors SBP and BMI were observed to be significant predictors of IOP. 


\section{Conclusion}

The findings of present study have depicted the multivariable of IOP and its variable relationship with various systemic risk factors. Thus, the measurement of IOP is essential in all the patients with variable demographic, anthropometric, or systemic profile.

\section{References}

1. Friedman DS, Wilson MR, Liebmann JM, Fechtner RD, Weinreb RN (2004) An evidence-based assessment of risk factors for the progression of ocular hypertension and glaucoma. Am J Ophthalmol 138: 19-31.

2. American Academy of Ophthalmology (2003) Intraocular pressure and aqueous humor dynamics. In: Liesegang TJ, Deutsch TA, Grand MG, Basic and clinical science course. Section 10: Glaucoma. San Francisco: American Academy of Ophthalmology, 14-24.

3. Zheng Y, Cheung CYL, Wong TY, Mitchell P, Aung T (2010) Influence of height, weight, and body mass index on optic disc parameters. Invest Ophthalmol Vis Sci 51: 2998-3002.

4. Gabelt BT, Kaufman PL (2003) Aqueous humor hydrodynamics. In: Kaufman PL, Alm A, Adler's Physiology of the Eye. (10 ${ }^{\text {th }}$ edn), St. Louis: Mosby, 237-289.

5. Allingham RR, Damji KF, Freedman S, Moroi SE, Shafranov G, et al. (2005) Cellular and molecular biology of aqueous humor dynamics. In: Allingham RR, Damji KF, Freedman S, Moroi SE, Shafranov G, et al., Shields' Textbook of Glaucoma. ( $5^{\text {th }}$ edn), Lippincott Williams \& Wilkins, Philadelphia, 5-35.

6. WHO expert consultation (2004) Appropriate body-mass index for Asian populations and its implications for policy and intervention strategies. The Lancet 363: 157-163.

7. Wong TT, Wong TY, Foster PJ, Crowston JG, Fong CW, et al. (2009) The relationship of intraocular pressure with age, systolic blood pressure, and central corneal thickness in an asian population. Invest Ophthalmol Vis Sci 50: 4097-4102.

8. Tomoyose E, Higa A, Sakai H, Sawaguchi S, Iwase A, et al. (2010) Intraocular pressure and related systemic and ocular biometric factors in a population-based study in Japan: the Kumejima study. Am J Ophthalmol 150: 279-286.
9. Zainab H, Iqbal Z, Naz MA, Awan AH, Ishaq M (2014) Relationship between intraocular pressure and body mass index. Pak Armed Forces Med J 64: 391-394.

10. Wang YX, Xu L, Zhang XH, You QS, Zhao L, et al. (2013) Five-Year Change in Intraocular Pressure Associated with Changes in Arterial Blood Pressure and Body Mass Index. The Beijing Eye Study. PLoS ONE 8: e77180.

11. Hashemi $H$, Khabazkhoob M, Emamian MH, Shariati M, Yekta A, et al. (2016) Distribution of intraocular pressure and its determinants in an Iranian adult population. Int $\mathrm{J}$ Ophthalmol 9: 1207-1214.

12. Lee JY, Yim HB, Kang KY, Lee NY (2017) Associations between Intraocular Pressure and Systemic Parameters according to the KNHNES 2008-2011. J Korean Ophthalmol Soc 58: 430-436.

13. Wu SY, Nemesure B, Hennis A, Leske MC; Barbados Eye Studies Group (2006) Nine-Year Changes in Intraocular Pressure: The Barbados Eye Studies. Arch Ophthalmol 124: 1631-1636.

14. Ngo S, Harris A, Siesky BA, Schroeder A, Eckert G, et al. (2013) Blood pressure, ocular perfusion pressure, and body mass index in glaucoma patients. Eur $\mathrm{J}$ Ophthalmol 23: 664-669.

15. Memarzadeh F, Ying-Lai M, Azen SP, Varma R, Los Angles Latino Eye Study Group (2008) Associations with Intraocular Pressure in Latinos: The Los Angeles Latino Eye Study. Am J Ophthalmol 146: 69-76.

16. American Academy of Ophthalmology. Aqueous Humor Formation.

17. Bengtsson $B$ (1972) Some factors affecting the distribution of intraocular pressures in a population. Acta Ophthalmol (Copenh) 50: 33-46.

18. Bulpitt CJ, Hodes C, Everitt MG (1975) Intraocular pressure and systemic blood pressure in the elderly. $\mathrm{Br} \mathrm{J}$ Ophthalmol 59: $717-720$.

19. Kim MJ, Park KH, Kim CY, Jeoung JW, Kim SH (2014) The distribution of intraocular pressure and associated systemic factors in a Korean population: The Korea National Health and Nutrition Examination Survey. Acta Ophthalmol 92: e507-e513. 